\title{
Geographical information systems in the management of the 2009-2010 emergency oral anti-rabies vaccination of foxes in north-eastern Italy
}

\author{
Paolo Mulatti, Nicola Ferrè, Tommaso Patregnani, Lebana Bonfanti, Stefano Marangon \\ Istituto Zooprofilattico Sperimentale delle Venezie, Viale dell’Università 10, 35020, Legnaro, Padua, Italy
}

\begin{abstract}
Emergency oral fox vaccination campaigns, targeting a recent rabies epidemic in wild foxes (Vulpes vulpes) in north-eastern Italy, were implemented twice, first in the winter of 2009 and then in the spring of 2010. Following on an unsuccessful manual bait distribution campaign, vaccine baits were aerially distributed by helicopters using a satellite-navigated, computer-supported, automatic bait drop system. The flight paths were traced with distance of 500-1,000 m from one another to optimise helicopter missions and guarantee homogeneous coverage of the vaccination area. The vaccine distribution was evaluated by superimposing a $1 \mathrm{~km}$-step grid and weighing the number of baits per cell. The implementation of a geographical information system for the management of vaccine distribution proved to be useful, both for the planning and execution phases, of the campaigns. It supported effective management of the flights and allowed near real-time monitoring of the campaigns. In addition, it facilitated the identification of areas with suboptimal bait density that would require additional flights or supplementary, manual distribution.
\end{abstract}

Keywords: rabies, foxes, wildlife, aerial vaccination, geographical information systems, Italy.

\section{Introduction}

The latest Italian case of rabies in wild foxes (Vulpes vulpes) was diagnosed in 1995 and the Country had been. classified as "rabies-free" since 1997. However, on 17 October 2008, the National Reference Centre identified a rabid fox in the municipality of Resia, located in the Friuli-Venezia Giulia region (FVG) in north- eastern Italy. Partial sequencing of the isolated rabies virus (RABV) strains showed a 100\% sequence identity with RABV isolates in Slovenia, Croatia and other West Balkan countries (De Benedictis et al., 2008). Following detection of the disease in foxes and its rapid spread in the fauna, three oral fox vaccination (OFV) campaigns were organised and conducted in FVG by manual distribution of vaccine baits. Despite these efforts, the disease spread westward to the Veneto region (November 2009), eventually reaching the autonomous provinces of Trento and Bolzano in early 2010 (Capello et al., 2010). Up to 9 September 2010 , a total of 284 rabies cases were diagnosed, i.e. 8 in Trento, 5 in Bolzano, 58 in FVG and 213 in Veneto (National Reference Centre for Rabies, Istituto

Corresponding author:

Paolo Mulatti

Istituto Zooprofilattico Sperimentale delle Venezie

Viale dell'Università 10, 35020, Legnaro, Padua, Italy

Tel. +39049808 4253; Fax +390498830268

E-mail: pmulatti@izsvenezie.it
Zooprofilattico Sperimentale delle Venezie - IZSVe, Legnaro, Italy).

To control the infection and minimise the risk of human exposure, two emergency OFV campaigns were implemented, the first in December 2009 and the other in April 2010. In both these campaigns, aerial distribution of vaccine baits was attempted in accordance with European Union (EU) guidelines (European Commission, 2002).

Aerial vaccination by using fixed-wings aircrafts and helicopters allow a precise territorial coverage and a faster distribution of baits in comparison to manual distribution, which also requires a thorough organisation and the involvement of a strong human resource (European Commission, 2002). The introduction of aerial distribution in OFV campaigns in 1988 in France drastically reduced the incidence of rabies over 6 years (Vauillame et al., 1998). Aerial distribution systems are indeed able to reach a high proportion of foxes over large areas (Johnston et al., 1988), and with lower costs per $\mathrm{km}^{2}$ than manual vaccination (Vauillame et al., 1998).

Due to the general geography of the Italian regions involved, helicopters were used as they permit superior manoeuvrability and better territorial coverage in hilly and mountainous areas. A satellite-navigated, computer-supported automatic system was used to adjust the spacing between the bait drops depending on the helicopter forward speed (Vos et al., 2001; 
Selhorst et al., 2006). This approach ensured a constant and homogeneous release of baits, including recording of the geographical coordinates of each drop. The main constraints were the special characteristics of the terrain, i.e. orography (the geography of mountainous areas), hydrography, presence of urbanised areas and the limited resistance of the vaccine to repeated freeze-thaw cycles (Pastoret et al., 1996). These factors, combined with the need to guarantee a homogeneous distribution of baits between 20 and 30 baits $/ \mathrm{km}^{2}$, depending on the fox population densities (European Commission, 2002), called for the design and application of a reliable strategy. In order to maximise success and minimise costs, an approach strongly relying on geographical information systems (GIS) was selected.

In this paper we describe the development of a local GIS dedicated to the management of OFV campaigns. Case studies, highlighting the obstacles faced and the measures adopted to address them, are presented.

\section{Materials and methods}

Data

Base maps, covering the FVG and Veneto regions and the autonomous provinces of Trento and Bolzano, were collated and used for planning and managing the vaccination operations. These maps included:

(i) administrative boundaries up to local administrative unit 2 (LAU 2), i.e. municipality level, scale 1:250,000 - Italian Ministry for the Environment, Land and Sea (IMELS) - National Cartographic Portal (PCN);

(ii) hydrography (rivers, lakes and other water basins), scale 1:250,000 (IMELS - Institute for Environmental Protection and Research - ISPRA);

(iii) urbanised areas, scale 1:10,000; and

(iv) orography of the area, extracted from a digital elevation model (DEM - SRTM 2000) (Farr et al., 2004).

A database was created for storing information obtained from the dropping machine. The automated system allowed the recording of the precise geographical location of each bait in an encrypted file. Moreover, an electronic metronome connected to a global positioning system (GPS) (Garmin ${ }^{\circledR}$ GPSMAP ${ }^{\circledR}$ 296) allowed adjusting the dropping tempo to the speed of the helicopter, providing a strong likelihood of homogeneous bait coverage (Vos et al., 2001). Beside the coordinates that were recorded in the reference World Geodetic System of 1984 (WGS84), the date and time of each drop were also recorded. On a daily basis, the decrypted files were imported into a MS Access ${ }^{\odot}$ database to be subsequently imported into the ESRI ${ }^{\circledR}$ ArcMAPTM GIS software. A shapefile was thus created for each single flight. This organisation of the available data allowed analysis and evaluation of the bait density down to the level of a single flight.

\section{Definition of vaccination areas}

The area to be covered by the OFV programme was determined according to the EU guidelines (European Commission, 2002) and included both infected areas and those at-risk for rabies introduction. The winter vaccination area was defined by a $50 \mathrm{~km}$ buffer zone around the geographical location of the most southern and the most western findings of rabies-positive foxes, extending it to natural or artificial barriers. The southern limit was considered to be the highway that crosses the Veneto region, up to the Piave River. The western boundary was conservatively designed to be located $6 \mathrm{~km}$ west of the Adige River, and included the eastern part of the autonomous provinces of Trento and Bolzano. To the east, the aerial vaccination area was extended to the administrative boundary of Veneto because the FVG region had implemented a manual vaccination campaign (completed by the second week of January 2010) across the whole region.

Due to the limited resistance of the vaccine to freezethaw cycles, an altitude threshold needed to be defined. The mean winter freezing point, i.e. the altitude at which $0{ }^{\circ} \mathrm{C}$ is reached, was estimated at 1,000 $\mathrm{m}$ above the mean sea level (MSL) based on previous records. The suitable area (SA) for vaccine distribution was not only selected by excluding areas above the threshold altitude, but also zones where foxes were unlikely to be found (i.e. rivers and lakes) and where baits could not be dropped (i.e. urban settlements). The SA was defined as the area where vaccine administration was possible and where it could be more effective due to the likely presence of foxes and the higher chances of vaccine stability.

Once the aerial vaccination operations were over, areas with a lower than optimal bait density were indentified (see the paragraph Procedures for evaluating territorial coverage for further details). Those areas were considered for complementary manual distribution of vaccine baits. Depending on the geomorphologic characteristics of the territory, baits were distributed by hand while walking along footpaths or from a moving car while driving along roads that were accurately selected. A GPS instrument was provided to 
each vaccination team, and each path followed was recorded. The distribution frequency depended on the number of baits needed to reach the target density.

\section{The winter vaccination campaign}

The gross vaccination area for the winter campaign was slightly larger than $18,200 \mathrm{~km}^{2}$. It included only part of the region consisting of Veneto and the autonomous provinces of Trento and Bolzano (Fig. 1). The SA, designed to be covered by flights (i.e. the area up to $1,000 \mathrm{~m}$ above MSL, excluding urbanised areas, drainage basins/rivers), was $8,150 \mathrm{~km}^{2}$ (Fig. 1). Flight paths were provided only for the plain areas. A total of 21 flights were traced covering between 182 and $372 \mathrm{~km}$ (Fig. 2). The vaccination campaign started on
28 December 2009. Up to 10 January 2010, a total of 232,300 baits were dropped in the SA $(126,000$ and 106,300 in the plains and the mountain areas, respectively).

\section{The spring vaccination campaign}

The area selected for the first part of the spring vaccination campaign (from 23 April to 15 May) was about $29,700 \mathrm{~km}^{2}$, and included part of the Veneto and FVG regions and the whole autonomous provinces of Trento and Bolzano (Fig. 3). The SA in this case was slightly more than $17,000 \mathrm{~km}^{2}$ (Fig. 3). A total of about 170 flights were traced for the mountainous and plain areas, ranging between 115 and 380 linear $\mathrm{km}$. Figure 4 shows an example of the routes traced.

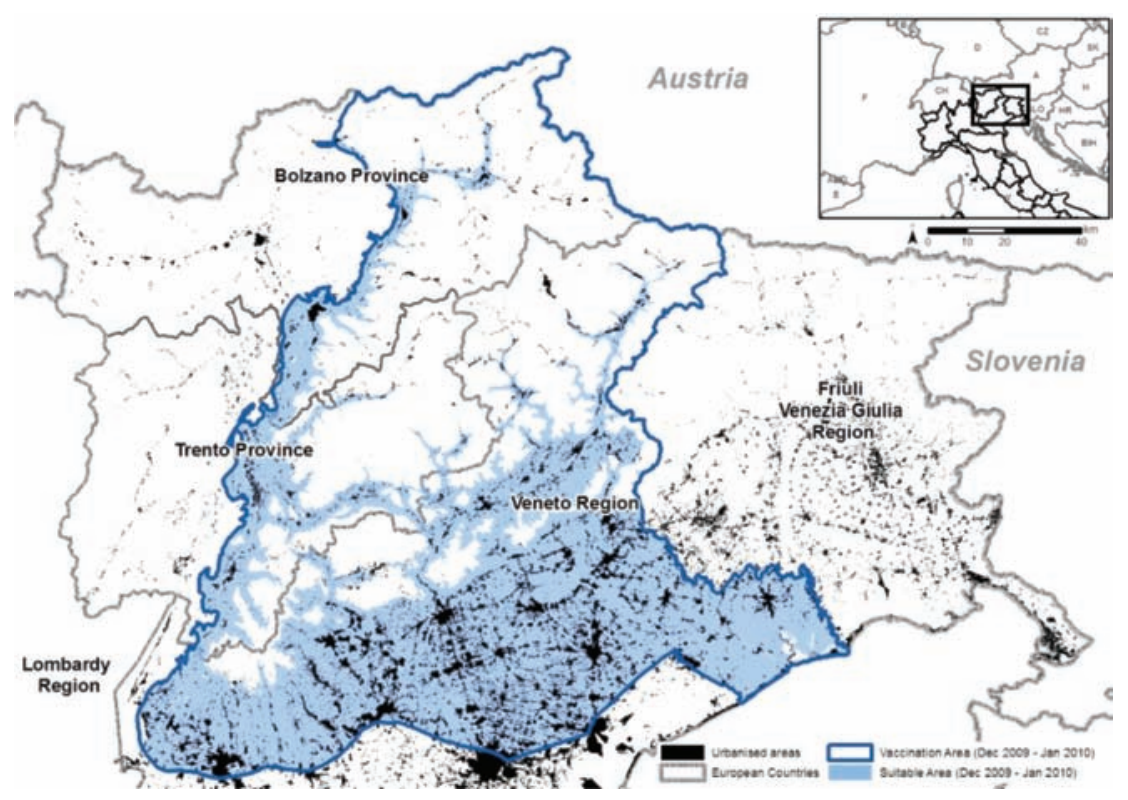

Fig. 1. Vaccination and SAs for the winter emergency aerial oral fox vaccination in Italy (December 2009 - January 2010).

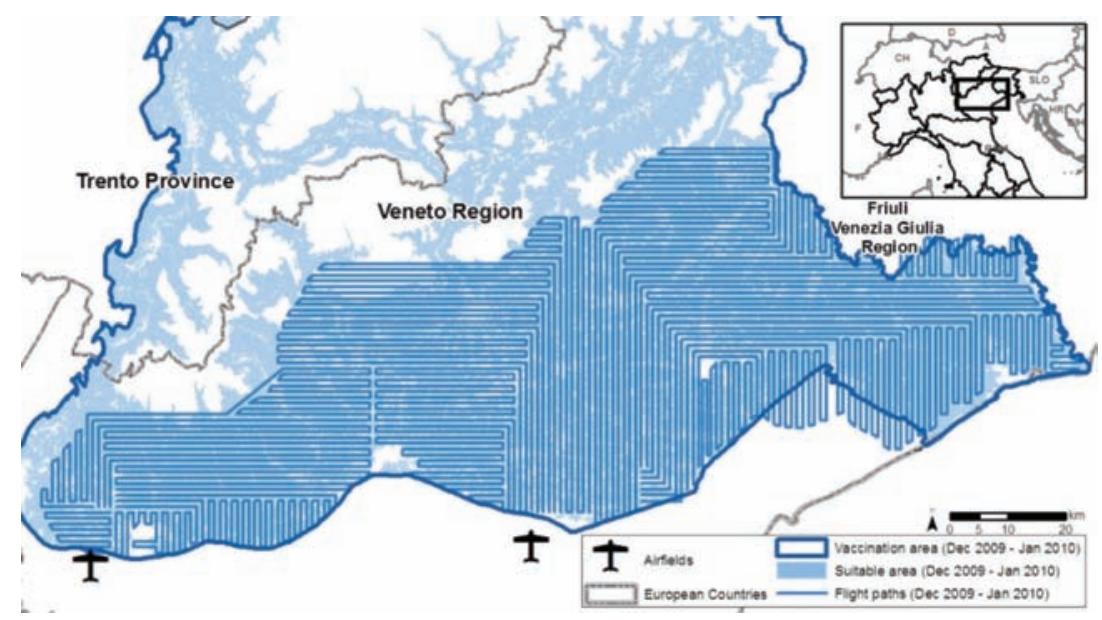

Fig. 2. Flight paths for the plain areas traced for the winter vaccination campaign in Italy (December 2009 - January 2010). 


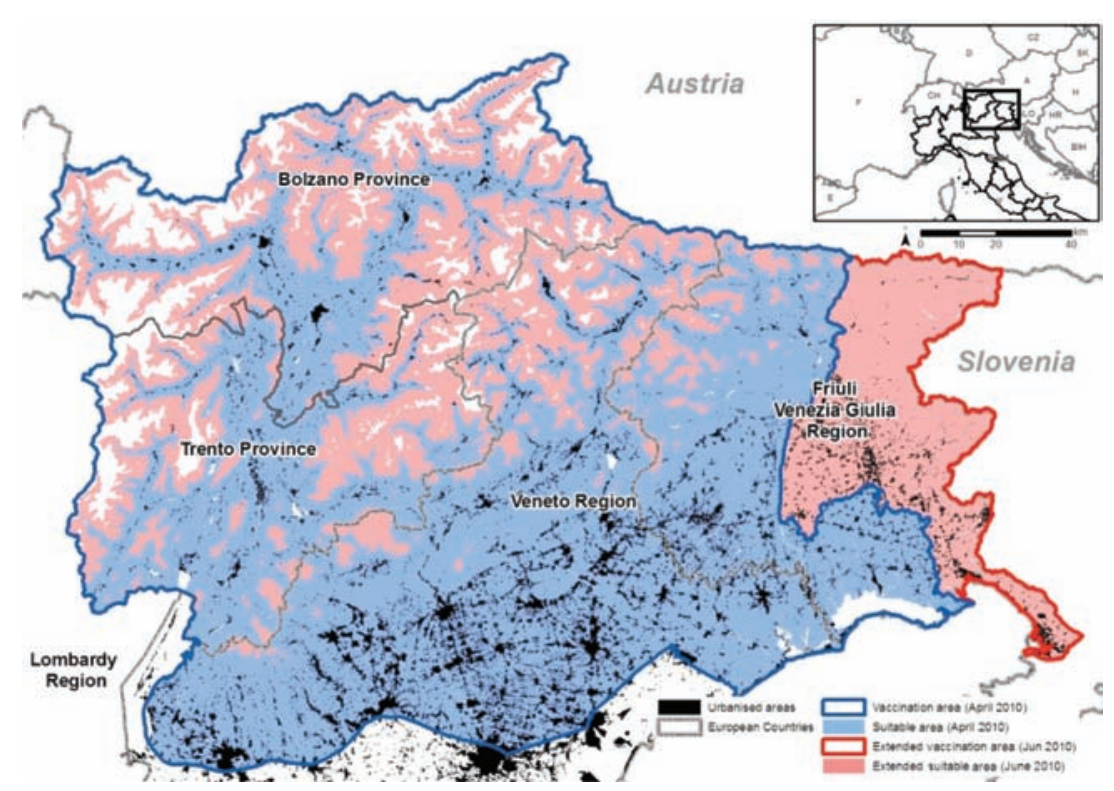

Fig. 3. Vaccination and SAs for the spring emergency aerial OFV campaign in Italy (April - June 2010). The blue area represents the first part of the campaign (23 April - 15 May 2010), with a threshold altitude of 1,500 m above MSL. The red area shows the extended vaccination area (24 May - 18 June 2010) after including the whole FVG area of and raising the threshold altitude to 2,300 $\mathrm{m}$ above MSL.

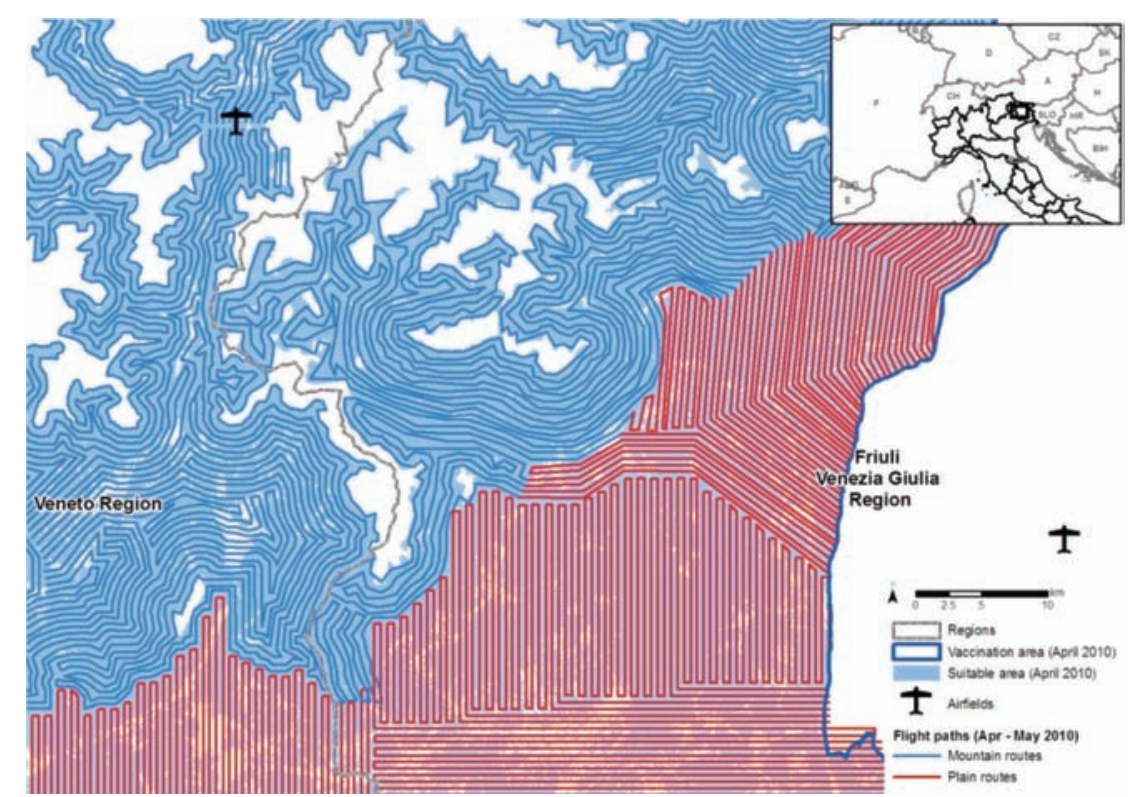

Fig. 4. Example of flight paths traced for the spring vaccination campaign in Italy (April - June 2010). Red lines show the flight paths for the plain areas, blue lines are for the mountainous areas.

Due to the spread of the infection to the eastern part of Trento and Bolzano in the first months of 2010, the spring vaccination area was eventually extended to include the entire territory of these two provinces. The western part of the FVG region was also included in this campaign on the basis of the several manual vaccinations carried out in different parts of this region. In addition, the currently warmer climate conditions allowed raising the threshold altitude from 1,000 to $1,500 \mathrm{~m}$ above MSL. Later on (from 24 May to 18
June 2010), due to the evolution of the epidemiological situation and the identification of rabies-positive foxes above the altitude threshold (Mulatti et al., 2010), the spring vaccination area was further extended to include areas up to 2,300 $\mathrm{m}$ above MSL. Also the remaining part of the FVG region, up to the Slovenian border, was included. The SA was again calculated with the exclusion of urbanised areas, river/drainage basins and mountainous zones above the threshold altitude. 
After extending the area with about $3,000 \mathrm{~km}^{2}$, it totalled $32,800 \mathrm{~km}^{2}$, while the SA was increased by more than $10,000 \mathrm{~km}^{2}$ to include the whole FVG region and all altitudes between 1,500 and 2,300 m above MSL. The total SA for the spring vaccination campaign was $27,950 \mathrm{~km}^{2}$ (Fig. 3). A total of 20 new routes were traced for the plain areas of the FVG region (including connecting flights), while the mountainous areas were subdivided into 25 sub-zones, delimited by segmented lines to be covered by aerial distribution. Examples of the new approach to the flight paths tracing is given in Figure 5.

\section{Definition of flight paths}

For the winter vaccination campaign, only the flight paths for the plains (i.e. areas located at altitudes up to $600 \mathrm{~m}$ above MSL) were defined. The lines were designed to optimise the helicopter missions. The major constraints in drawing the flight paths were the operating range of the helicopters and the technical characteristics of the on-board GPS unit, into which the flight paths needed to be uploaded. The flight lines were designed to be 1,000 $\mathrm{m}$ apart and since the GPS unit only accepted routes with a maximum of 30 waypoints (DePriest, 2003), the threshold of 30 turn points was set. Flight paths were thus represented by segmented lines along which helicopters had to change direction at 30 times maximum. The routes for the mountainous and hilly areas, i.e. areas located at altitudes above $600 \mathrm{~m}$ above MSL, were not pre-defined but instead agreed on with the pilots during the drop operation. The threshold altitude was used as refer- ence to create parallel routes $500 \mathrm{~m}$ apart to attempt homogeneous bait coverage. The target bait density was 25 baits $/ \mathrm{km}^{2}$, a level that corresponded to 25 and 13 baits per linear $\mathrm{km}$ for the plains and mountain routes, respectively.

The flight routes for the spring vaccination campaign were given to the pilots for the whole vaccination area, which was partitioned into eight districts based on geography, the administrative boundaries and the density of the urbanised areas. For each district, an airfield and a warehouse for storing the baits were identified. An approach, similar to the one used in the winter campaign, was applied to trace the flight routes for the plain areas, whereas the paths defined for the mountainous areas followed the threshold altitude, thus covering the SA by concentric lines. In order to increase vaccination efficacy here, the distance between routes was reduced to $500 \mathrm{~m}$ as suggested by Thulke et al. (2004), and this inter-route distance was kept both for the plains and the mountain areas. Since the mountain routes largely exceeded the vertex threshold number, the lines could not be directly uploaded to the on-board GPS device preventing the pilots from following the flight paths as originally planned. Instead, the routes and the ground context maps were uploaded to a different GPS device (Trimble ${ }^{\circledR}$ Juno ${ }^{\text {TM }}$ GPS-PDA) and a supervisor, or technician, was aboard following the trace and directing the pilot accordingly. However, while this approach improved flight management in the mountainous areas, the involvement of additional staff and the absence of computer support impaired the transfer of flight directions to the pilots, leading to manoeuvring

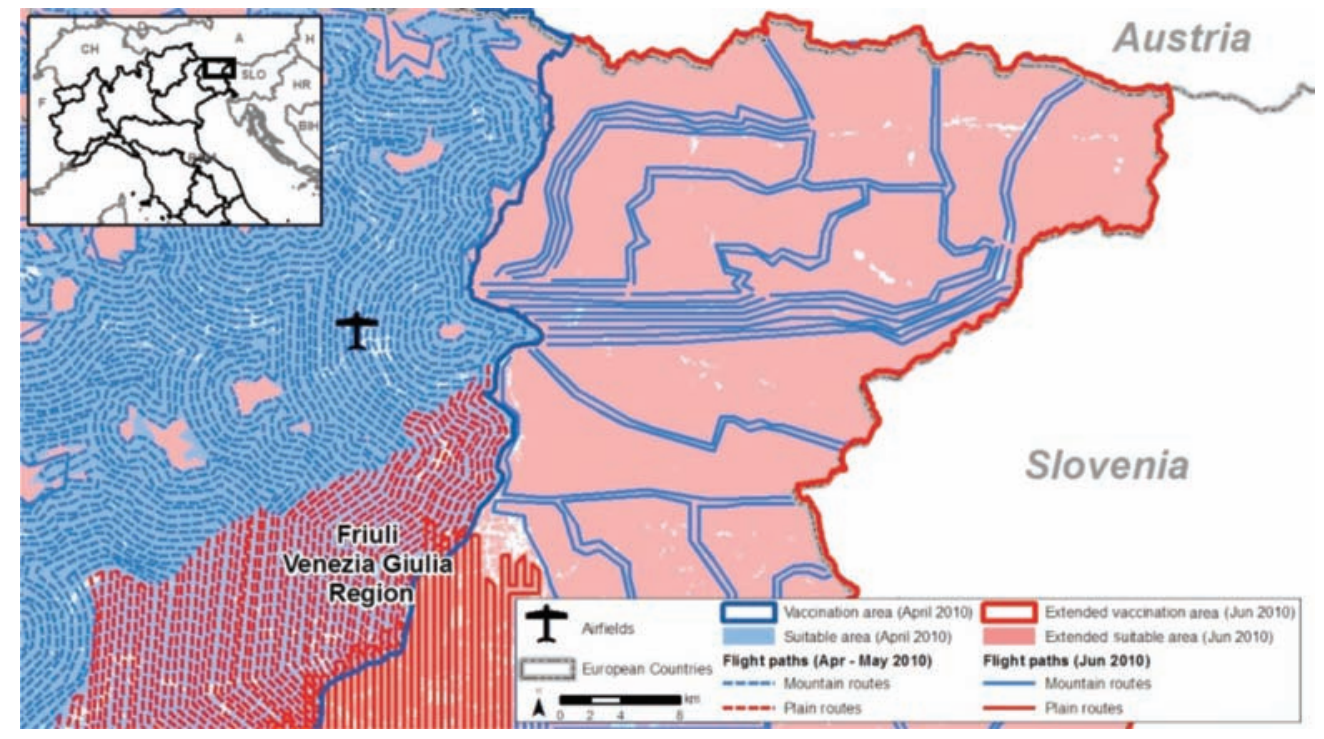

Fig. 5. Example of flight paths traced across the extended vaccination area during the spring campaign (May - June 2010). 
errors and a lower baits drops/flight time ratio.

When the vaccination area was extended from 24 May 2010 to include the mountainous areas, a new approach was required to avoid the need for supervisors to be on board the aircraft. Instead of flight paths, sub-areas were defined using fragments of lines with at maximum of 30 vertices to contour them. It was then possible to upload the area to the on-board GPS device, thus allowing pilots to locate the exact bait dropping locations. Each area corresponded to a single flight but connecting paths were traced to increase the effective use of the helicopters also during transfers.

\section{Procedures for evaluating territorial coverage}

A first rough idea of both the number of distributed baits and the efficacy of the flights, in terms of territorial coverage, was acquired by mapping the shapefiles obtained from the encrypted files created by the GPS device linked to the bait-drop machine. The bait density was then calculated by superimposing a $1 \mathrm{~km}$-step grid over the vaccination areas and counting the number of baits dropped into each cell. The grid was overlaid on the SA map for each vaccination campaign and only the baits dropped in the SA were considered effective and included in the bait density estimate.

For the winter campaign, only the raw number of baits per cell (i.e. bait $/ \mathrm{km}^{2}$ ) was considered when estimating the density. The results of the point-in-polygon estimation were eventually arranged into five consecutive classes: 0 baits $/ \mathrm{km}^{2}, 1-10$ baits $/ \mathrm{km}^{2}, 10-20$ baits $/ \mathrm{km}^{2}, 20-30$ baits $/ \mathrm{km}^{2}$, and $>30$ baits $/ \mathrm{km}^{2}$. This was done to allow rapid identification of the areas where the bait density was not sufficient or suboptimal (such as classes 1 and 2). Since the raw estimation of baits per cell produced an excessively fragmented picture, the map was converted to the ESRI ${ }^{\circledR}$ GRID format and a neighbourhood mean was calculated on a $3 \times 3$ base (Focal Statistic tool Spatial Analyst Toolbox, ESRI ${ }^{\circledR}$ ArcMap $^{\mathrm{TM}}$ ) (McCoy and Johnston, 2002). A smoothed map was obtained where the value of each pixel could be calculated as the mean of the pixel itself and those surrounding it. Reclassified, smoothed maps were used to highlight cells with a suboptimal density of baits.

The lessons learned during the first vaccination campaign helped implement a more reliable procedure for evaluating bait coverage during the spring vaccination. In the April-June campaign, different target bait densities were set for the plains and the mountainous areas (20 and 26 baits $/ \mathrm{km}^{2}$, respectively). A greater risk for rabies spread was indeed assumed for the mountainous areas, due to the exclusion of large zones above $1,000 \mathrm{~m}$ above MSL in the winter vaccination campaign and the increased number of positive foxes found at higher altitudes after the first aerial OFV campaign (Capello et al., 2010; Mulatti et al., 2010). An evaluation grid, similar to the one used in the winter campaign, was superimposed over the spring vaccination area. The fractions of SA falling into each cell were calculated and appended as attributes to the grid. An ESRI ${ }^{\circledR}$ GRID image was then produced with a cell resolution of $1 \times 1 \mathrm{~km}$ by converting the grid using the SA fractions as the values to be considered. Another GRID image was created with the same resolution and origin, reporting if each cell belonged to a mountain or a plain area. The bait density was calculated for each flight, as data were available, through the Point Density tool of the Spatial Analyst Toolbox of ESRI $^{\circledR}$ ArcMap $^{\text {TM }}$ (McCoy and Johnston, 2002). The results were summed to the SA overall bait density. The raw estimates were then weighed by the SA and the mountain/plain rasters, through the MapAlgebra functions. The resulting raster image allowed assessing the real bait density per $\mathrm{km}^{2}$ of SA, standardised for the mountain/plain target densities. It was therefore possible to classify bait densities in both mountain and plain areas using the same scale. The ranges of baits for the mountainous and plain areas, respectively, were used to create five classes as shown in Table 1.

Table 1. Classification of bait density for mountainous and plain areas

\begin{tabular}{lccl}
\hline No. & $\begin{array}{c}\text { Mountainous areas } \\
\left(\text { bait } / \mathrm{km}^{2}\right)\end{array}$ & $\begin{array}{c}\text { Plain areas } \\
\left(\text { bait } / \mathrm{km}^{2}\right)\end{array}$ & Class \\
\hline 1 & $0-10$ & $0-8$ & Insufficient \\
1 & $10-17$ & $8-13$ & Scarce \\
2 & $17-23$ & $13-18$ & Suboptimal \\
3 & $23-26$ & $18-20$ & Optimal \\
5 & $>26$ & $>20$ & Overabundant \\
\hline
\end{tabular}

The density analysis was performed on a daily basis in the spring vaccination campaign as this allowed rapid identification of areas with non-optimal bait density and swift implementation of adequate interventions such as aerial redistribution of baits to reach the target density level. For each update, a smoothed map was created through a $3 \times 3$ pixels mean to share the results with decision makers and pilots.

After the aerial distribution, an autocorrelation analysis was performed on the raw data grid to identify the clustered cells with a non-optimal weighed number of baits $/ \mathrm{km}^{2}$. The Getis-Ord $G_{i}^{*}(d)$ routine, present in the ESRI ${ }^{\circledR}$ ArcMap $^{\mathrm{TM}}$ Spatial Statistics Toolbox, was used by considering the weighed values 
of baits $/ \mathrm{km}^{2}$ as the variable of interest and including only the first order of neighbours as the threshold distance (Mitchell, 2005). The clusters of cells with a suboptimal bait density (i.e. cold spots) were identified as having a $Z$ score equal to, or lower than, -1.96 $(\mathrm{P} \leq 0.05)$, indicating cells with low bait density surrounded by cells with similar, low values (Getis and Ord, 1992; Ord and Getis, 1995). The grid was than overlaid onto the SA map for the spring vaccination and the neighbouring cells were merged to obtain the overall area of each "cold spot". Areas greater than 1 $\mathrm{km}^{2}$ were then classified to be eligible for manual distribution or, in case of particularly vast zones, further flights.

\section{Results}

\section{The winter vaccination campaign}

Despite careful flight planning, the bait density evaluations detected a not fully satisfactory distribution of baits. In particular, a very low density, even absence of baits, was observed in the hilly zones between the mountains and the plains, and also in some mountainous areas (Fig. 6a). A total of about $1,250 \mathrm{~km}^{2}(15.3 \%$ of the total SA) had been unsatisfactorily covered. Further flights were therefore needed. Over 3 days, 48,200 more baits were released in those areas, leading to a more homogeneous distribution (Fig. 6b). The definitive (final) density maps were then used to identify the cell of the evaluation grid where the bait density was still not optimal (about $500 \mathrm{~km}^{2}, 6.1 \%$ of the

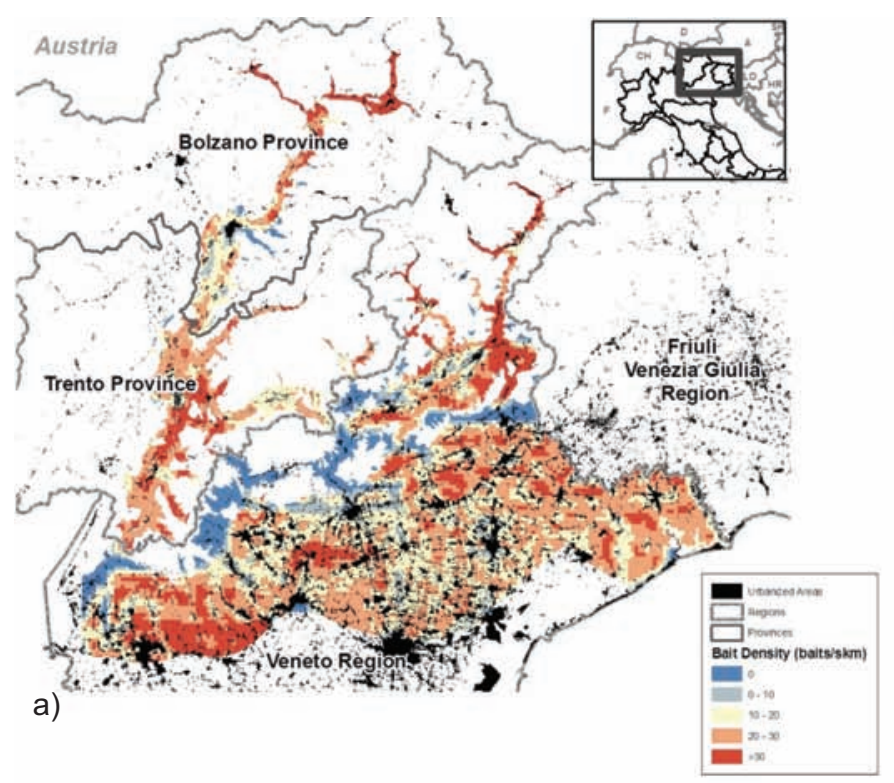

total SA). Only classes 1 and 2 were taken into account, and more detailed maps were produced for those areas to better organise the complementary manual distribution of baits.

The first experiences with the aerial OFV proved positive, reaching an optimal mean density of baits per $\mathrm{km}^{2}$ in the vaccination areas. The good territorial coverage during the winter campaign was confirmed by the reduction of fox rabies cases in the vaccination area (Capello et al., 2010).

\section{The spring vaccination campaign}

Up to 15 May 2010, nearly 295,000 baits had been released, but evidence concerning the fox population dynamics and the evolution of the epidemic prompted the suspension of bait distribution about this time until the vaccination area had been increased.

The second part of the spring vaccination lasted until 28 June 2010 and about 309,000 additional baits were dropped. The approximate number of baits released during the whole spring vaccination campaign was 604,000 . The weighed density of baits is shown in Figure 7. The Getis-Ord $G_{i}{ }^{*}(d)$ showed that a total of 3,036 cells had a significantly low-bait density. After filtering for areas greater than $1 \mathrm{~km}^{2}$, the total suboptimal area was about $1,640 \mathrm{~km}^{2}(5.9 \%$ of the total SA) (Fig. 8). Georeferenced results of the manual distribution of baits were available only for the Belluno province in Veneto. Maps showing the corrections made by the manual distribution are given in Figure 9.

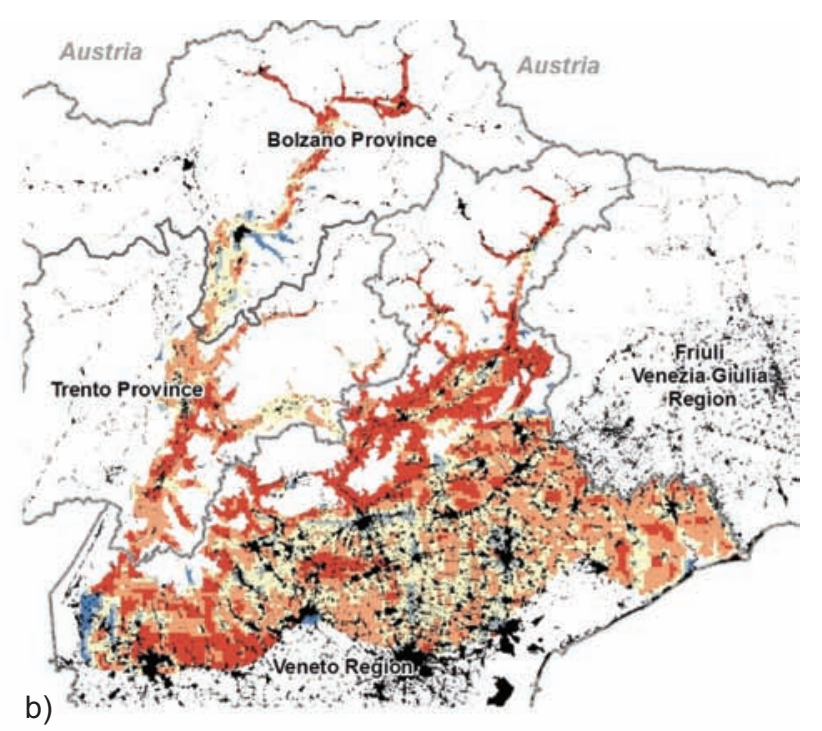

Fig. 6. Bait density of the winter vaccination campaign. a) Bait density at 10 January 2010. b) Bait density after further flights in areas with previous suboptimal density. 


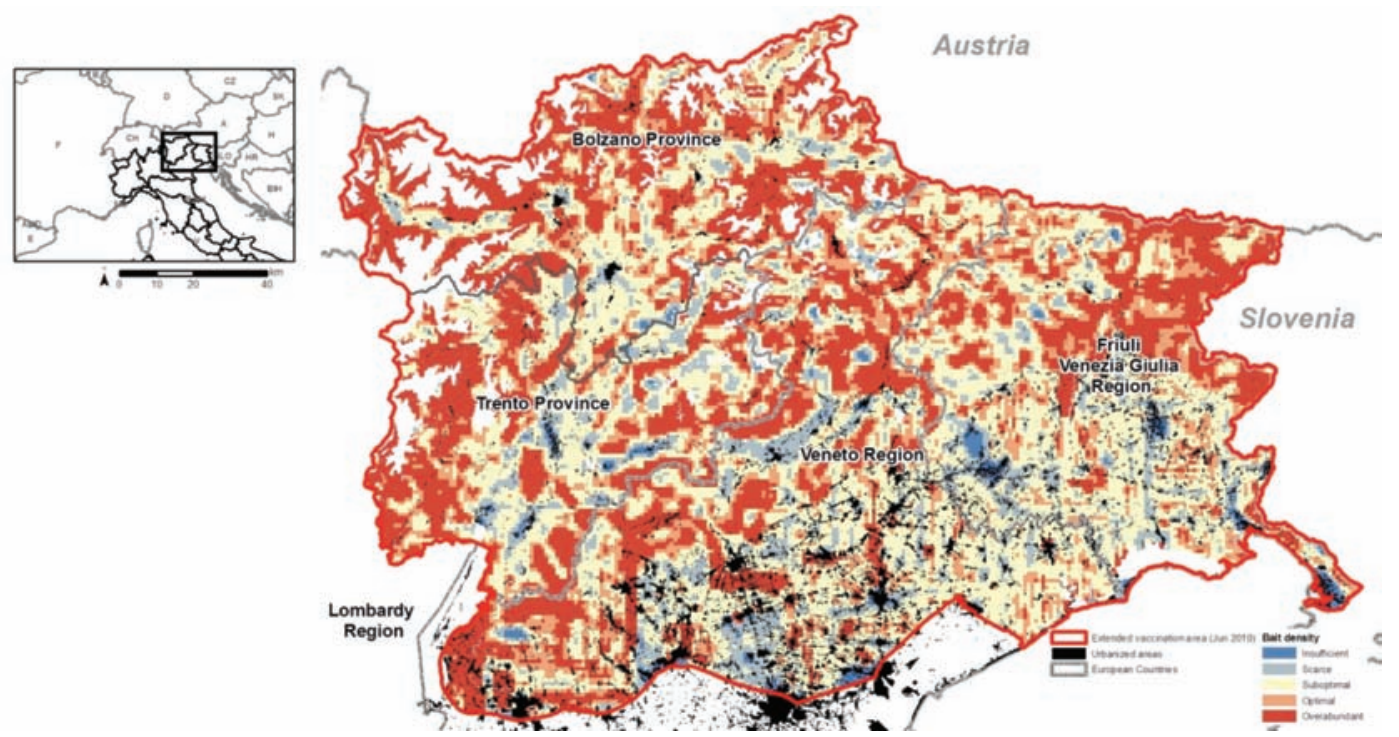

Fig. 7. Results of the bait density analysis for the spring OFV campaign.

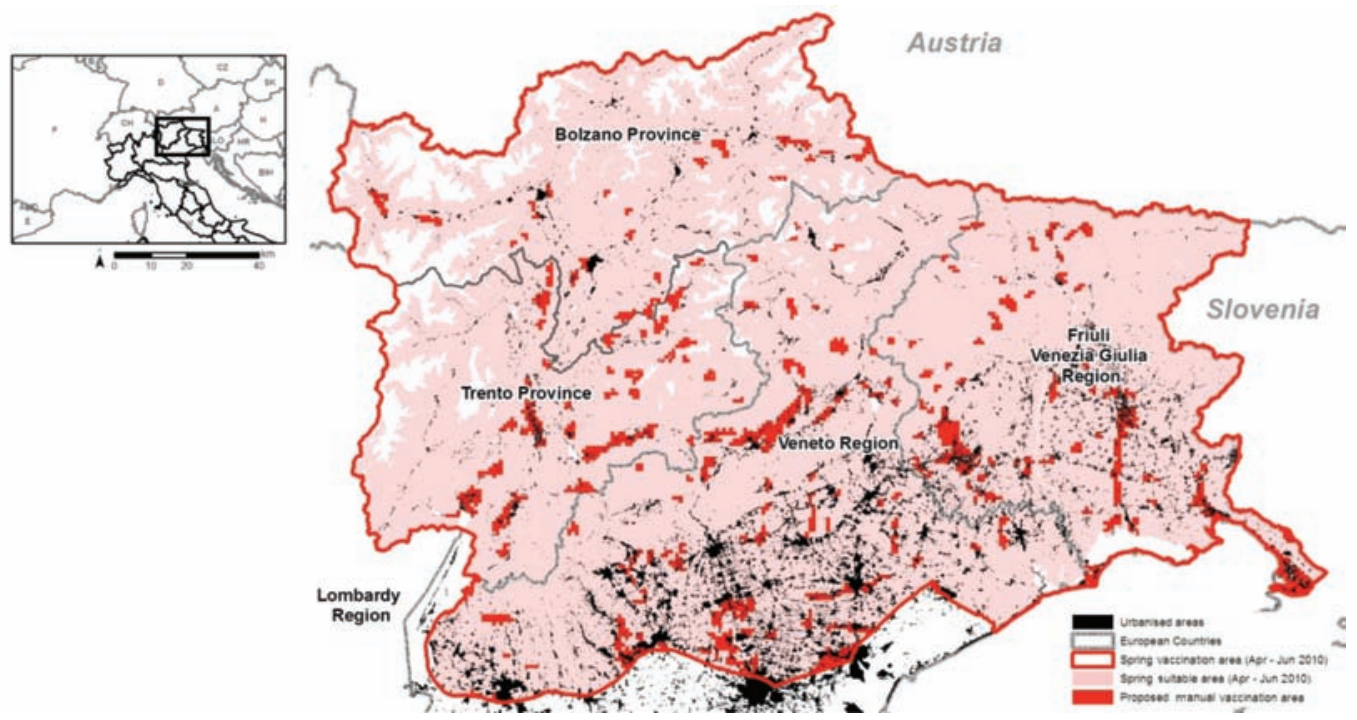

Fig. 8. Results of the autocorrelation analysis to identify the areas suboptimally covered by aerial bait distribution during the spring OFV campaign.

a)

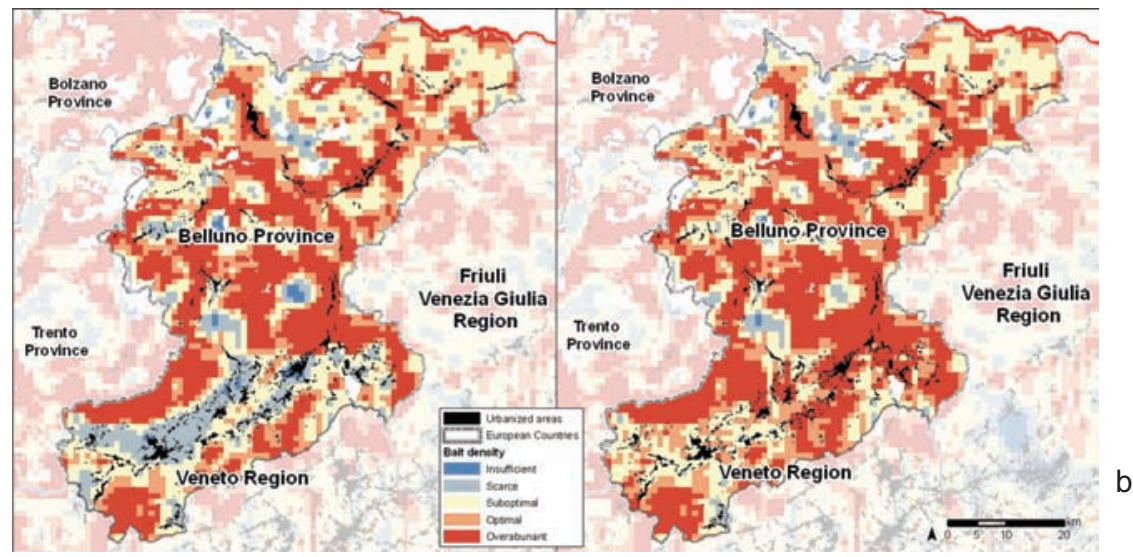

Fig. 9. Outcome of the manual bait distribution complementing the April - June 2010 aerial vaccination: a) bait density resulting from the aerial distribution of vaccine baits; b) bait density calculated after the integration of manual bait distribution. Only the northern province of Belluno (Veneto region) is showed. 


\section{Discussion}

The introduction of rabies into Italy in 2008 was not totally unexpected. The risk in the northern and eastern border regions of Italy has long been recognised as infected foxes appear to have crossed the border from Slovenia and Austria during previous epidemics (Mutinelli et al., 2004; De Benedictis et al., 2008). The continuous presence of the infection in wild fox populations of Slovenia, and particularly in Croatia, must also be taken into account (Hostnik et al., 2006; WHO, 2010). Moreover, there is a dense fox population in the territory, even if knowledge of its dynamics and movements is still limited. Indeed, the rapidity and extent of the spread of the disease were unpredictable, posing a serious challenge to the Italian veterinary public health authority and calling for a broader control approach. This led to OFV campaigns based on aerial bait distribution, which made it possible to cover a large territory within a limited period of time. EU guidelines were followed but, due to lack of detailed information of the fox populations, the number of baits per $\mathrm{km}^{2}$ was increased. Helicopters were resorted to because the broad mountain ridges seriously hampered the use of fixed-wing airplanes. Better manoeuvrability was achieved in the mountainous areas including improved distribution of baits in narrow valleys and near small villages.

The employment of an automatic machine for the bait drops, synchronised with the flight speed, helped optimise the distribution by reducing the number of operators and ensuring a homogeneous release of baits. However, several issues remained to be addressed, adverse weather conditions and natural accidents in particular. For example, the re-activation of the Icelandic volcano Eyjafjallajökull on 20 March, 2010 delayed vaccine operations, while the presence of small urbanised areas hampered the distribution of baits in their proximity, preventing the achievement of the target bait density. Moreover, at the beginning of the spring vaccination campaign, technical issues related to the different vaccine baits used, and the need to adapt the automatic drop machine to them, impaired the correct evaluation of the bait density for the initial flights. On the other hand, the later incorporation of a dedicated GPS device allowed the recording of geographical data and the integration of the recorded data into the GIS-based system employed.

The use of GIS not only proved necessary in the planning and execution phases of the vaccination campaigns, but was also useful for the evaluation of its outcome. The implemented system was used to draw the flight paths, thus optimising the operations based on the landscape characteristics. Furthermore, the recording of drop locations allowed a near real-time evaluation of bait distribution as well as detection of areas with low bait density, crucial information for follow-up activities. Similarly, spatial statistical tools implemented after the end of the flight operations contributed to defining areas more suitable for vaccination by manual distribution due to various environmental or technical issues. Nevertheless, the dedicated GIS system is still not completely developed. Beside the aforementioned technical issues related to the drop machine, other problems may arise and partially impair territorial coverage planning and evaluation. Detailed base maps are needed (with at least at a nominal scale of $1: 10,000$ ) to allow fully reliable estimates of the SAs. Base layers carrying information on river/drainage basins and urbanised areas must be readily available and be as up-to-date as possible. Another constraint was the non-optimal integration between the GIS system and the GPS device on board the helicopters, which meant that files had to be converted to the appropriate formats before being uploaded. The next step will be to integrate the GIS system with the GPS by using a GPS with a personal digital assistant (PDA) or a tablet that would make it possible to follow the flight paths on a display, calculating bait density in real-time.

The creation of smoothed maps, where the value of each pixel was calculated as the mean of the pixel itself and those surrounding it, was done to facilitate sharing the bait density maps with decision makers in a clearer format. The reclassified maps contributed to highlight areas with a suboptimal density in need of a second aerial or a complementary manual distribution of baits.

A new vaccination campaign has recently been organised, and new approaches implemented with regard to drawing flight paths. In particular, the orientation of the flight paths was rotated by 45 degrees with respect to the evaluation grid, a move that should help prevent errors when calculating bait density because routes can overlap cell borders. The results should direct future efforts in ways improving the GISbased bait density evaluation system.

\section{Acknowledgements}

The authors wish to thank the Italian Ministry of Health for logistic support, and the Veterinary Services of FVG, Veneto and of the provinces of Trento and Bolzano, for their collaboration and the organisation of the on-field operations. 


\section{References}

Capello K, Mulatti P, Comin A, Gagliazzo L, Guberti V, Citterio C, De Benedictis P, Lorenzetto M, Costanzi C, Vio P, Zambotto P, Ferri G, Mutinelli F, Bonfanti L, Marangon S, 2010. Impact of emergency oral rabies vaccination of foxes in northeastern Italy, 28 December 2009-20 January 2010: preliminary evaluation. Euro Surveill 15, 19617.

De Benedictis P, Gallo T, Iob A, Coassin R, Squecco G, Ferri G, D'Ancona F, Marangon S, Capua I, Mutinelli F, 2008. Emergence of fox rabies in north-eastern Italy. Euro Surveill 13, 19033.

DePriest D, 2003. A GPS User Manual: Working with Garmin Receivers. 1st Books Library. Available online at: http://www.gpsinformation.org/dale/wgarmin.htm\#toc (accessed on 15 February 2011).

European Commission, 2002. The oral vaccination of foxes against rabies. Report of the Scientific Committee on Animal Health and Animal Welfare, 23 October 2002.

Farr TG, Rosen PA, Caro E, Crippen R, Duren R, Hensley S, Kobrick M, Paller M, Rodriguez E, Roth L, Seal D, Shaffer S, Shimada J, Umland J, Werner M, Oskin M, Burbank D, Alsdorf D, 2004. The Shuttle Radar Topography Mission. Rev Geophys 45, 1-33.

Getis A, Ord JK, 1992. The analysis of spatial association by use of distance statistics. Geogr Anal 24, 189-206.

Hostnik P, Toplak I, Barlic-Maganja D, Grom J, Bidovec A, 2006. Control of rabies in Slovenia. J Wildlife Dis 42, 459465.

Johnston DH, Voigt DR, MacInnes CD, Bachmann P, Lawson KF, Rupprecht CE, 1988. An aerial baiting system for the distribution of attenuated or recombinant rabies vaccines for foxes, raccoons, and skunks. Rev Infect Dis 10, 660-664.

McCoy J, Johnston K, 2002. Using ArcGIS Spatial Analyst. ESRI Press, Redlands, California, USA.

Mitchell A, 2005. The ESRI Guide to GIS Analysis - Volume 2: Spatial Measurements \& Statistics. ESRI Press, Redlands,
California, USA.

Mulatti P, Gagliazzo L, Di Martino G, Lorenzetto M, Mutinelli F, Bonfanti L, Marangon S, 2010. Rabies hotspots above the threshold altitude of the 2009 - 2010 oral fox vaccination campaign in Italy. GEOVET 2010, 1-3 December 2010, Sydney, Australia.

Mutinelli F, Stankov S, Hristovski M, Seimenis A, Theoharakou H, Vodopija I 2004. Rabies in Italy, Yugoslavia, Croatia, Bosnia, Slovenia, Macedonia, Albania and Greece. In: King AA, Fooks AR, Aubert M, Wandeler AI, editors. Historical perspectives of rabies in Europe and the Mediterranean Basin. OIE, Paris, France, pp. 93-118.

Ord JK, Getis A, 1995. Local spatial autocorrelation statistics: distributional issues and an application. Geogr Anal 27, 286-306.

Pastoret PP, Brochier B, Languet B, Duret C, Chappuis G, Desmettre PP, 1996. Stability of recombinant rabies vaccine in veterinary use. Dev Biol (Basel) 87, 245-249.

Selhorst T, Müller T, Bätza HJ, 2006. Epidemiological analysis of setbacks in oral vaccination in the final stage of fox rabies elimination in densely populated areas in Germany. Dev Biol (Basel) 125, 127-132.

Thulke HH, Selhorst T, Müller T, Wyszomirski T, Müller U, Breitenmoser U, 2004. Assessing anti-rabies baiting - what happens on the ground? BMC Infect Dis 4, 9.

Vuillaume P, Bruyere V, Aubert M., 1998. Comparison of the effectiveness of two protocols of antirabies bait distribution for foxes (Vulpes vulpes). Vet Res 29, 537-546.

Vos A, Mührke HH, Holzhofer E, Gschwender P, Schuster P, 2001. A satellite navigated and computer-supported fully automatic system for distributing oral vaccine-baits against rabies: SURVIS. Proceedings of the $12^{\text {th }}$ Rabies in the Americas conference, November 12-16, 2001, Peterborough, Ontario, Canada, p. 66.

WHO, 2010. Rabies Bulletin Europe. WHO 2010, 34, JanuaryMarch. Available from: http://www.who-rabies-bulletin.org/ Journal/Default.aspx? Issue= 2010_1 (accessed on 15 February 2010) 